\title{
Typology of Innovative Behavior of Entrepreneurs as a Development Potential of the Region
}

\section{Kristina A. LOGUN}

\author{
Ph.D. (Pedagogics)
}

Associate Professor of the Department of Mathematics and Computer Science

Institute of Digital Technologies and Economics

North-Eastern State University

4 Commune Str., Magadan, 685000, Russia

krislog@mail.ru

\begin{abstract}
The article presents the results of a sociological study the aim of which is to study the innovative behavior of entrepreneurs in the region. The research objectives included the study of the concept of "innovative behavior of entrepreneurs", the formation and justification of a typological model of innovative behavior, the definition and study of the components of the model (personal and social innovative orientation), the determination of the characteristics of the social types of entrepreneurs on the basis of the constructed model. The methodological basis of the study is the framework of factor analysis, typological analysis, as well as modern concepts of innovative behavior and entrepreneurship. As a result of the study, the operationalization of the concept of "innovative behavior of young entrepreneurs" is developed, the methods of factor analysis that allow constructing factor models and studying social types of entrepreneurs based on a typology and typological analysis are considered. The hypothesis of the existence of social types of innovative behavior of entrepreneurs, in which the dominant factors are personal and social innovative orientation, is confirmed. The analysis of social types is presented, the prospects for further research to increase the development potential of the region are shown.
\end{abstract}

Keywords: innovative behavior; innovative focus; typology of innovative behavior; entrepreneurship; factor analysis; typological analysis.

\section{Introduction}

In the current context, solving the problems of regional development is particularly relevant. In our opinion, the solution to these problems is facilitated by the study of a special group of the population - entrepreneurs. In this regard, a study of the innovative behavior of entrepreneurs of Magadan was conducted. We investigated young entrepreneurs of this city, methods of factor analysis were applied, a typology of innovative behavior of young entrepreneurs was carried out on the basis of factor analysis, and social types of entrepreneurs were identified and studied. The results of this study contribute to the study of the development potential of the region, and also show the possibilities of using typological analysis in order to reveal further strategies for the development of the region. As methods there were applied factor analysis, typological analysis.

\section{Results}

The innovative behavior of young entrepreneurs should be understood as a special type of behavior that provides the ability to anticipate the possible changes in environmental conditions, as well as the ability to prepare for them in such a way as to use in their favor (Islamutdinov, Shangaraev, 2011). There are scientific publications on the theoretical and methodological foundations of this concept (Molostova, 2010). So, for example, the main characteristics of innovative behavior are highlighted: focus; focus on overcoming obstacles, rather than worries 
about them; flexibility, implying an adequate response to a rapidly changing environment; a combination of spontaneity with the possibility of arbitrary regulation; perseverance, but not turning into aggressiveness. So, for example, the main characteristics of innovative behavior are highlighted: targeting; focus on overcoming the obstacles, rather than worries about them; flexibility, which implies an adequate response to a rapidly changing environment; a combination of spontaneity with the possibility of arbitrary regulation; perseverance, but not turning into aggression. Innovative behavior of entrepreneurs is most often considered a form of economic or market behavior. Accordingly, innovative behavior can be understood as a kind of economic behavior, which involves a special way, the nature of economic actions, which consists in targeted, and carried out not once, but on an ongoing basis, initiating, evaluating the effectiveness, selecting and implementing innovative projects and activities. As a kind of market behavior, innovative behavior implies the prevalence of strategic goals over the tactical goals, the preference for nonprice competitive methods (primarily quality competition) and a combination of intensive interaction of firms with the research and public sector and irreconcilable competition among themselves.

In the Magadan region, various programs are being implemented aimed at developing the innovative economy of the region (Inform. Kolyma agency, 2014). It is worth noting that the Magadan region began to actively develop innovative activities since 2007 (Golobokova, 2010). Currently, a regional innovation system, which is a set of interacting subjects of innovative activity and its infrastructure, as well as regional government bodies that ensure the implementation of innovation policy, is actively developing. At the same time, the development of innovation is not possible without the active participation of small businesses and entrepreneurs. To date, there are a number of publications devoted to the development of innovative entrepreneurship, for example Basenko and Dianova (2019), Polyansky (2017). Among the factors influencing the development of innovative activity, the authors single out financial and economic, technological (availability of financial reserves, material and technical means, advanced technologies; motivation for innovative activities; availability of the necessary infrastructure), organizational and managerial (flexibility of organizational structures; the prevalence of horizontal flows of information; autonomy; democratic management style; the formation of targeted creative groups), administrative and legal (state support for innovation; legislative measures encouraging innovative activity), social and cultural (providing opportunities for self-realization; the availability of creative labor; moral encouragement; public recognition; favorable moral and psychological climate) (Basenko, Dianova, 2019). The materials of the international conference devoted to the socio-economic and marketing aspects of innovative entrepreneurship (Polyansky, 2017), raise current issues related to this concept. They cover various areas of innovative entrepreneurship, offer mechanisms to increase the innovative component of entrepreneurship. Among the monographs devoted to the innovative development of entrepreneurship, we note, for example (Asaul, Zagidullina, Emelyanov, Faltinsky, 2016), which states that an innovation policy consists of an innovative concept, an innovative strategy, an innovation management system, an innovative environment, infrastructural and instrumental support for the production and commercialization of innovative products. The most important component of the innovation policy is to provide conditions for the expansion of innovation in priority areas of the country's development in an open market economy.

Meanwhile, as the analysis of publications shows, the typology of innovative behavior of entrepreneurs is not given research attention.

In our view, the need to study the principles and mechanisms of the formation of innovative activity of young entrepreneurs has determined the need for a more detailed study of the social types of innovative behavior of young entrepreneurs in the region.

In the process of our research, the operationalization of the concept of "innovative behavior of young entrepreneurs" was developed. We have identified two groups of factors: subjective 
(personal) and objective. Subjective factors include: innovative personality traits, innovative personality potential, self-development, personal growth, socio-demographic characteristics. Objective factors include: changing macro environment conditions, factors of social progress, competitive environment. More details about the operationalization can be found in the publication of the authors Trushevskaya and Logun (2018).

The study of innovative behavior was attended by 56 young entrepreneurs aged 19 to 35 years.

On the question of the understanding of "innovative behavior" young entrepreneurs gave the following answers: lateral thinking (26.8\%), neoplasm (8.9\%), development of new skills $(8.9 \%)$, ability to forecast, innovate (5.4\%), the desire for professional self-education and self-development (5.4\%), proactive type of behavior (5.4\%) and others.

Analysis of the answers to the question "How do you evaluate your experience in innovation activity?" showed that more than a third of respondents (36.96\%) rate their experience in innovation activity as successful, $30.43 \%$ of them as completely successful, and $28.26 \%$ of them as neutral and only $4.35 \%$ as not successful. Most young entrepreneurs $(76.79 \%)$ have no experience of participating in innovation support contests, and only $23.21 \%$ of entrepreneurs have such experience. The results of the study showed that most young entrepreneurs (62.5\%) expressed an average degree of desire to participate in the innovation competition, $14.29 \%$ expressed a weak degree of desire, and $23.21 \%$ - a strong degree. According to a survey of young entrepreneurs, about a quarter of Magadan's young entrepreneurs have the innovative behavior $(25.23 \%)$. To the question "Can you say that you have this kind of behavior?" the majority of respondents $(82.14 \%)$ answered positively. We see that the ratio of the percentage of entrepreneurs with, according to the opinion of the surveyed young entrepreneurs, innovative behavior, from the percentage of selfidentification with this behavior of the surveyed young entrepreneurs is significantly different. To the question "Do you strive to enrich your innovative experience?" the majority of respondents $(64.29 \%)$ answered positively.

When analyzing the results, it was suggested that the overall innovative behavior of young entrepreneurs was heterogeneous. In this regard, for a more detailed analysis of innovative behavior, we used the method of factor analysis.

The following hypothesis was formulated and confirmed in the study: there are social types of young entrepreneurs in accordance with the typology of innovative behavior, in which the dominant factors are personal and social innovative orientation. More details can be found in the publication of the authors Trushevskaya and Logun (2018).

To test this hypothesis, we conducted a factor analysis, which is used to study the correlation of a large number of interrelated quantitative variables with the subsequent grouping of variables into a small number of factors (Kline, 1994; Cattell, 1966; Howitt \& Cramer, 2011; Pett, Lackey, \& Sullivan, 2003). This statistical method allows us to give both a meaningful interpretation of each factor, based on the meaning of variables, and to express a large number of variables through several factors. The analysis of the main components is recommended to be carried out in the case when the main task of the researcher is to determine the minimum number of factors that make the maximum contribution to the dispersion of data in order to use them in the multivariate analysis in the future. These factors are called the main components.

For our study, it is quite logical to assume that some variables will correlate with each other, since they measure one characteristic of the respondent, namely its innovative orientation, although in different ways. If there are too many variables in the study $(\mathrm{x} 1, \mathrm{x} 2, \ldots, \mathrm{xp})$, and some of them are interconnected, then it is advisable to reduce the data complexity by reducing the number of variables. To do this, we use the principal component method, which creates several new variables 
$\mathrm{y} 1, \mathrm{y} 2, \ldots, \mathrm{yp}$, each of which is a linear combination of the original variables $\mathrm{x} 1, \mathrm{x} 2, \ldots, \mathrm{xp}$. The variables y1, y2,.., yp are called the main components or factors.

The specificity of this method is that, firstly, during the computational processes, all the main components are simultaneously obtained and their number is initially equal to the number of original variables (in our case, it is 21 variables), and secondly, it postulates the possibility of complete decomposition of the variance of all original variables, i.e. its full explanation through latent factors (consolidated signs).

Thus, a factor is an artificial statistical indicator that arises as a result of special transformations of the correlation matrix. The procedure for extracting factors is called factorization of the matrix. As a result of factorization, a different number of factors can be extracted from the correlation matrix up to a number equal to the number of original variables. However, factors determined as a result of factorization, as a rule, are not equivalent in value.

To process and analyze the data we used the IBM SPSS Statistics (SPSS - Statistical Package for the Social Sciences) computer program (Field, 2009), which allows you to extract new valuable information from data quickly and easily, solve a wide range of research and business tasks.

The questionnaire proposed to the respondents contained questions related to the personal qualities of young entrepreneurs. Respondents were asked to evaluate the availability of these qualities on a 5-point scale from 1 to 5: 1 - you do not have, 2 - you have almost none, 3 - you have and you don't have, 4 - you have, but not fully, 5 - you have it fully. It was carried out the procedure of factor analysis. As a result, the following data were obtained. The Kaiser-Meyer-Olkin Test (KMO) allows us to evaluate how fully the constructed factor model describes the structure of the respondents' answers to the questionnaire asks that represent the studied variables. The results of the KMO test range from 0 (the factor model is absolutely not applicable) to 1 (the factor model perfectly describes the data structure). The results of the factor analysis can be considered valid if the value of the KMO test is more than 0.5. In this case, the value of the KMO test is 0.633 , which indicates the acceptability of the constructed factor model. Bartlett's sphericity criterion allows checking the equality of variances of several samples (two or more) (Bartlett, 1937). In our case, the significance of the Bartlett test is 0,000 , which means that the original hypothesis $\mathrm{H} 0$ can be rejected with a margin of error of 0,000 . Thereby, the original hypothesis $\mathrm{H} 0$ is rejected, and the alternative hypothesis $\mathrm{H} 1$ is accepted. There is a correlation between the variables involved in factor analysis, so we can argue that the correlation between the variables exists and it is possible their grouping based on the correlation tightness. The test results of the KMO and Bartlett reveal the suitability of the initial data of our model for factor analysis. Such a mathematical procedure as the rotation of factors allows us to explain the meaningful sense of the main components identified at the previous stage, which explain most of the total variance of variables. The most common rotation method, in which factors are independent or orthogonal towards each other, so that the values of variables of one factor do not correlate with values of other factors, is a Varimax rotation. This rotation method was used in our study.

As a result of factor analysis, two factors that combine personal qualities were formed.

\section{Factor 1 - Personal innovation focus:}

- Diligence, commitment (0.792)

- Ability to negotiate $(0.779)$

- Intuition (0.757)

- Poise, practicality $(0.704)$

- Savvy, ingenuity (0.679)

- Quick decision making (0.671)

- Self-confidence (0.663) 
- Enthusiasm (0.654)

- Leadership, activity (0.605)

- Ability to find innovative solutions (0.528)

- Analytical mind (0.424)

\section{Factor 2 - Social innovation focus:}

- Awareness of the value of innovation processes $(0.800)$

- Ability to innovate (0.783)

- Psychological flexibility (0.768)

- Social mobility (0.762)

- Ability to predict $(0.742)$

- Economic mobility (0.715)

- Responsibility for decision-making (0.599)

- Creativity (0.578)

- Honesty, decency, law-abiding $(0,554)$

- Intelligence, experience (0.425)

The first factor, and this is obviously, combined all the provisions related to the individual (or personal) characteristics. Based on the positive correlation coefficients and the participating variables with the factor, as well as taking into account the polarity of the values of the variables (a large value means complete agreement), a large value of the factor means agreement with this position. The second factor includes those provisions that indicate interaction with the external environment, i.e. characterize social innovation focus.

Thus, we can talk about the existence of a typology of innovative behavior of young entrepreneurs in accordance with the selected factors: factor 1 - Personal innovation focus, factor 2 - Social innovation focus. This typology is based on determining the level of significance of the relevant personality traits of young entrepreneurs.

The constructed two-factor model allows us to combine young entrepreneurs in 4 groups within these two factors:

the first coordinate quarter is for respondents with a high personal and high social innovation focus (group 1);

the second coordinate quarter is for respondents with a low personal and high social innovation focus (group 2);

the third coordinate quarter is for respondents with a low personal and low social innovation focus (group 3);

the fourth coordinate quarter is for respondents with a high personal and low social innovation focus (group 4).

We will show the features of the dedicated social types of young entrepreneurs in answering the question about the experience of participating in innovation contests.

We will find out if there are differences in the experience of participation in these innovation contests among representatives of the dedicated social types of young entrepreneurs. Received data confirm our assumptions: the first group contains the largest percentage of young entrepreneurs with experience in participating in innovation support competitions $(37.5 \%)$.

In this regard, it can be argued that the first group (i.e., the first social type) includes young entrepreneurs with a more marked innovation focus. Such entrepreneurs prioritize not only making 
a profit, but also the possibility of self-expression through business, and getting satisfaction with their success. Getting maximum profit takes a back seat, giving way to the desire to achieve maximum success and getting satisfaction from their activities.

The second group (the second social type) includes young entrepreneurs with a less marked innovation focus and in this group there is the smallest percentage of young entrepreneurs with experience in participating in innovation competitions (7.7\%).

In the third and fourth groups, the percentage of participation in innovation competitions is about the same: in the third group $-25 \%$, in the fourth $-21.1 \%$. We can call these groups social types with a medium innovation focus. These groups include entrepreneurs whose activities are not without initiative. However, a high success rate is important for them, only then they agree to take risks.

The results of the study also show differences in seniority in the Association of Young Entrepreneurs in the social types that we have identified. In general, the data on the seniority in the Association of Young Entrepreneurs according to the sample are as follows: about a third of young entrepreneurs (33.93\%) are members of the Association for 2 years, a quarter of entrepreneurs (25\%) are members of the Association for 3 years, $17.86 \%$ of entrepreneurs have seniority in the Association for 1 year, $12.5 \%-5$ years, $7.14 \%-4$ years, $3.57 \%-6$ years. However, with a separate examination of each identified social group, the following data were obtained. So, in the first group of young entrepreneurs, the average seniority in the Association is about 3 years, the second group includes young entrepreneurs whose average seniority is 2.62 years, the average seniority of respondents in the third group is 2.63 years, and 2.68 years for the fourth group. That is, we can conclude that in the first group - with a more marked innovation focus - the experience in the Association is greater than in other groups.

\section{Discussion}

The data obtained during the study are new, as it is the first time when a typological analysis of the innovative behavior of entrepreneurs was carried out, the operationalization of this concept was developed, the social types of innovative behavior of entrepreneurs were described, a two-factor model with two factors - personal and social innovation focus - was justified and built, the possibilities of this research to study the innovative potential of the region were shown.

\section{Conclusion}

The study identified factors that regulate the innovative behavior of young entrepreneurs. Namely, it was proved that factors such as gender and age do not affect the innovative behavior of young entrepreneurs, and factors such as experience in participating in innovation competitions and seniority in the Association of Young Entrepreneurs are significant factors that influence innovative behavior. Social types of young entrepreneurs (based on a two-factor model that takes into account personal and social innovation focus) were identified and studied. Their further study may contribute to the successful innovative development of the region.

\section{References:}

Asaul, A.N., Zagidullina, G.M., Emelyanov, O.O., Faltinsky, R. A. (2016). Mechanisms for ensuring the innovative development of business subjects. In A. N. Asaul (Ed.). SPb.: ANO "IPEV". (in Russian)

Bartlett, M.S. (1937). Properties of sufficiency of statistical tests. Proc. Roy. Soc., Series A, 31, $268-282$. 
Basenko, V.P., Dianova, V.A. (2019). Instruments for the development of innovative entrepreneurship in the region. Scientific Bulletin of the Southern Institute of Management, 3(27), 66-72. (in Russian)

Cattell, R.B. (1966). The Scree Test for the Number of Factors. Multivariate Behavioral Research, 1(2), 245-276. https://doi.org/10.1207/s15327906mbr0102_10

Field, A. (2009). Discovering Statistics Using SPSS: Introducing Statistical Method (3rd ed.) Thousand Oaks, CA: Sage Publications.

Golobokova, G.M. (2010). Methodological approaches to the creation of a regional innovation system (RIS). Problems of the formation of the innovative economy of the region: materials of I scientific-practical conf. (Magadan, December 2-3, 2009), 78-82. (in Russian)

Howitt, D., Cramer, D. (2011). Introduction to statistics in psychology (5th ed.), Harlow, UK: Pearson. 362-379.

Inform. Kolyma agency. (2014). Magadan young researchers, thanks to targeted professional training, ensure the development of the economy of the entire region. (in Russian). Retrieved from http://www.kolyma.ru/index.php?newsid=47814

Islamutdinov, V.F., Shangaraev, R.G. (2011). To the question of the concept of innovative person. Issues of innovative economy, 4(4), 3-12. (in Russian)

Kline, P. (1994). An easy guide to factor analysis. London: Routledge.

Molostova, N.Yu. (2010). Theoretical and methodological foundations of the concept of "innovative behavior", Izvestiya Samara Scientific Center of the Russian Academy of Sciences, 12(5-1), 132-136. (in Russian)

Pett, M.A., Lackey, N.R., Sullivan, J.J. (2003) Making sense of factor analysis: The use of factor analysis for instrument development in health care research. London: SAGE.

Polyansky, K.K. (Ed.). (2017) Innovative entrepreneurship: socio-economic and marketing aspects: materials of the International Scientific and Practical Conference, April 28-29, 2017. Voronezh: Publishing and printing center "Scientific Book". (in Russian)

Trushevskaya, A.A., Logun, K.A. (2018). The factor model and typology of innovative behavior of young entrepreneurs. Problems of the modern economy, 2(66), 151-157. (in Russian) 